\title{
METHODS FOR FUZZY DEMAND ASSESSMENT FOR IT SPECIALTIES
}

\author{
Masuma Mammadova \\ Institute of Information Technology of the National Academy of Sciences of Azerbaijan \\ 9 B. Vahabzada str., Baku, Azerbaijan, AZ1141
}

\begin{abstract}
The rapid development of information technologies and their penetration into various spheres of human activity cause a sharply increased demand for IT specialists, in many countries of the world far exceeding the supply on them. High rates of technological transformation contribute to the diversification of the IT segment of the labor market, on the one hand, stimulate the disappearance of some and the emergence of new IT specialties, on the other. This creates a discrepancy between the structure of IT-related education and the labor market demand for IT specialists of the required profile and determines the relevance of developing methods for assessing the demand for IT specialties.

This article is devoted to the study and solution of the problem of identifying the demand for IT specialties in the absence of accurate and complete information about the situation in the IT market segment. For the assessment of IT specialties and their ranking by the degree of demand in the labor market, the tasks of making individual and group decisions in the context of fuzzy initial information are formulated and solved. The methodological basis of the tasks posed is multi-criteria decision support methods based on fuzzy relations of expert preferences.

The proposed approach as a mathematical tool for minimizing the structural imbalance of supply and demand for IT specialties is one of the components of the system of intellectual management of the labor market of IT specialists. The latter is designed to support the adoption of scientifically based management decisions to eliminate the mismatch of supply and demand in the IT segment of the labor market in professional, quantitative and qualitative sections.
\end{abstract}

Keywords: IT specialties, demand, supply, labor market, fuzzy source information, decision making.

DOI: $10.21303 / 2461-4262.2019 .00939$

\section{Introduction}

Currently, the special role of information technology (IT) in the development of both the global and national economies, stimulating the growth of productivity, competitiveness and innovation potential of industries and enterprises is beyond doubt. Large-scale digitalization and the transformation of information into a global resource have led to a sharply increased demand for IT professionals in the labor market, which in many countries around the world now far exceeds the supply for them. So, according to [1-3] in Europe, the demand for IT specialists is growing by about 3-4\% annually and is ahead of their supply. According to experts, the number of IT vacancies by 2025 may increase from 750 thousand to 1 million compared to 274 thousand in 2013. The shortage of IT specialists observed in almost all EU countries occurs against the background of a reduction in the number of people receiving the highest IT profile in Europe, as well as engineering and science education. Probably many of these potential vacancies will remain unfilled if measures are not taken to attract young people to IT education, retraining, on the one hand, to systematically update the structure of the IT professions and specialties, and accordingly, training programs, on the other hand. Growth in demand for IT professionals and their insufficient supply are also observed in such developed countries as the USA and Canada [4-6]. The CIS countries, including Azerbaijan, which are actively integrating into the global information society, also faced the problem of mismatch of supply and demand for IT specialists [7-9].

Analysis of the demand in the IT segment of the labor market in Azerbaijan, the calculation of the total number of IT specialists and their supply by the IT profile education system, as well as the number of IT specialists required to cover replacement, revealed a significant imbalance of these indicators [10-12]. The shortage of IT specialists is mainly covered by the influx into the IT industry of workers whose basic specialization does not coincide with the professional structure of their position (for example, representatives of professions that are potentially close to IT or are completely unrelated to IT work as an IT specialist this industry). 
Technological transformation of the IT sphere requires continuous updating of the professional knowledge and skills (competencies) of IT specialists. The opening of new jobs demanded by the digital economy, the expansion of digital labor markets and the growing number of virtual organizations determine the need for IT professionals with new professional competencies [13]. This causes the disappearance of some IT professions and specializations due to the obsolescence of a number of professional competencies and the emergence of others. However, the inert education system does not have time to respond to rapid technological changes in a timely manner, continuing to produce IT specialists, whose professional knowledge and skills do not correlate well with current and future labor market needs. At the same time, the IT industry has to constantly adapt to their rapidly changing requirements in order to maintain competitiveness in the global, national and local markets. All this contributes to the increasing mismatch between the IT-specific education system and the labor market and leads to a situation where, for a number of new IT specialties demanded in the labor market, not one university in the country trains specialists.

Today, the problem of identifying the structure and needs of the labor market in the context of professions and specialties is one of the most relevant and insufficiently studied in many countries, including Azerbaijan. It is not by chance that the issues of identifying supply and demand for various professions and specialties, reorienting the education system to the needs of the labor market in the country as priorities are reflected in a number of political documents [14-17]. They prioritized the need to solve such important tasks as identifying supply and demand for various professions and specialties; improving the training of personnel competitive in the labor market; reorientation of the education system to the needs of the labor market, i.e. on employers 'requirements for graduates' knowledge and skills, etc. In this context, the study of the structure of IT specialties from the standpoint of their relevance in the labor market is a rather important task.

\section{Approaches to demand assessment in the IT segment of the labor market in the context of IT occupations and specialties}

The aim of this article is development of methods for demand (necessaty) assessment for IT professions and specialties, which allow identifying the degree of demand for labor in the labor market, ranking them in order of increasing (decreasing) significance, determining the level of structural imbalance of supply and demand in the IT market segment labor.

Problem statement. There are a predetermined number of IT professions and specialties identified by examining the structure of the IT segment of the labor market. It is required to assess the need for IT specialties and their ranking (streamlining) from the most promising to low demand from the positions of demand in the labor market. Let's note that the ordering of the list of specialties takes into account the demand for a particular IT specialty as a whole, and not the likelihood of employment of each IT specialist.

The problem of assessing and selecting the most demanded IT labor specialties in the labor market falls under the category of weakly structured tasks that traditionally boil down to making decisions with fuzzy initial information $[18,19]$. This is due to the "soft" nature of the labor market itself as an object of management, as well as the formation of demand and supply for IT professions and specialties under the influence of a variety of uncertainties - incompleteness, inaccuracy, ambiguity of data. The lack of complete statistical information about the demand and supply of IT specialties, the difficulty of acquiring reliable information about the labor market status of IT specialists, the ambiguity of the system of indicators characterizing demand and supply, their quantitative and qualitative nature, high dynamism of the IT industry lead to an increase in the uncertainty of the initial information and reduce the effectiveness of management decisions made by traditional methods [20].

The task of demand assessment for IT specialties as weakly structured is in selection of the most demanded from a variety of IT specialties and is based on using the preferences of experts or decision makers. Experts are involved in the process of evaluating IT specialties (alternatives) for a set of attributes that form the degree of demand for a specialty in the market, and express preference relations for each of them, and the task of assessing the need for IT specialties can be reduced to streamlining alternatives with fuzzy initial information [18]. 
To assess the demand for IT specialties and their ordering according to the degree of demand in the IT segment of the labor market, methods of fuzzy multi-criteria adoption of individual and group expert decisions on the selection of priority IT specialties based on a fuzzy relational knowledge representation model have been proposed [21]. The practical implementation of methods for assessing the need for IT specialties was carried out on the basis of the list of the latter, formed during the study.

\section{The method of fuzzy multi-criteria adoption of individual expert decisions on the choice of priority IT specialties}

Let's there are many IT specialties that are subject to assessment and ranking in terms of their relevance in the labor market. Formally, this set can be described as a set of alternatives

$$
X=\left\{x_{1}, x_{2}, \ldots, x_{n}\right\}=\left\{x_{i}, i=\overline{1, n}\right\}
$$

each of which is characterized by a set of criteria

$$
K=\left\{k_{1}, k_{2}, \ldots, k_{m}\right\}=\left\{k_{j}, j=\overline{1, m}\right\} .
$$

The task of assessing the need for IT specialties with the greatest demand in the labor market is reduced to the task of choosing the best alternatives among the many assessed, taking into account the attitude of preferences of an individual expert.

The degree of satisfaction of the set of alternatives $\mathrm{X}$ to the criteria $\mathrm{K}$

$$
K=\left\{k_{j}, j=\overline{1, m}\right\}
$$

is determined by the set of membership functions

$$
\mu_{k_{j}}\left(x_{i}\right): X \times K \rightarrow[0,1], \quad j=\overline{1, m},
$$

where $\mu_{k_{j}}\left(x_{i}\right)$ expresses the satisfaction degree of the alternative $x_{i}$ by criterion $k_{j}$.

The choice of the best (non-dominated) alternative is reduced to a multicriteria problem of fuzzy mathematical programming, for the solution of which the Generalized Bellman-Zadeh approach $[18,22]$ is applicable. Moreover, the degree of belonging of alternatives to a fuzzy solution of the problem is equal to the minimum of these digits for all the criteria $K=\left\{k_{j}, j=\overline{1, m}\right\}$, $\Omega=\mathrm{k}_{1} \cap \mathrm{k}_{2} \cap \ldots \cap \mathrm{k}_{\mathrm{m}}$ :

$$
\mu_{\Omega}\left(x_{i}\right)=\min _{j=1, m} \mu_{k_{j}}\left(x_{i}\right), \quad i=\overline{1, n} \text {. }
$$

As the best (effective) alternative is selected $\mathrm{x}^{*}$, which has the highest value of the membership function:

$$
\mu_{\Omega}\left(x^{*}\right)=\max _{j=1, m} \mu_{k_{j}}, \quad\left(x_{i}\right)=\max _{i=1, n} \mu_{\Omega}\left(x_{i}\right) .
$$

This means that the IT specialty corresponding to this alternative is most in demand in the labor market.

In accordance with the values of the membership functions, expressing the degree of satisfaction of alternatives to the criteria, IT specializations are streamlined according to the degree of their demand in the labor market.

\section{The method of fuzzy multi-criteria group decision making on the choice of priority IT specialties}

In this case, the task of assessing the demand for IT specialties is reduced to the problem of choosing among the many evaluated alternatives the best, taking into account the relations of prefer- 
ences of several experts. The satisfaction degree of the set of alternatives $X$ to the set of criteria $\mathrm{K}$ is determined by the set of membership functions

$$
\phi_{k_{j}}\left(x_{i}\right): X \times K \rightarrow[0,1]
$$

Set of experts $G$ is formed by the decision maker, who is guided by his own opinion on the level of their competence. For each of the experts $g \rightarrow G$, a fuzzy preference relation is defined on the set of alternatives $X$, i. e. membership function of the form $\psi: X \times X \times G \rightarrow[0,1]$. Naturally, in the process of multi-criteria evaluation of alternatives, experts proceed from their own preference relations. The value $\psi\left(x_{i}, x_{j}, g\right)$ is interpreted as the degree of preference of the alternative $\mathrm{x}_{\mathrm{i}}$ to the alternative $x_{j}$, through the prism of the preferences of the expert $\mathrm{g}$ and is determined as follows:

$$
\psi\left(x_{i}, x_{j}, g\right)= \begin{cases}1-\left[\phi\left(x_{j}, g\right)-\phi\left(x_{i}, g\right)\right], & \text { if } \phi\left(x_{j}, g\right) \geq \phi\left(x_{i}, g\right) \\ 1, & \text { if } \phi\left(x_{j}, g\right) \leq \phi\left(x_{i}, g\right)\end{cases}
$$

where

$$
\varphi\left(x_{i}, g\right)=\min \left\{\varphi_{k_{j}}\left(x_{i}, g\right), j=\overline{1, m}\right\} .
$$

Using the expression (5) of each expert, a matrix of unclear preference relations of alternatives is determined.

On the other hand, the decision maker unequally evaluates the competence of experts invited by them to assess alternatives. This factor is reflected by the coefficient of competence of experts: $\gamma(g) \rightarrow[0,1]$, taking into account which from the expression

$$
v\left(g_{1}, g_{2}\right)= \begin{cases}1-\left[\gamma\left(g_{2}\right)-\gamma\left(g_{1}\right)\right], & \text { if } \gamma\left(g_{2}\right) \geq \gamma\left(g_{1}\right), \\ 1, & \text { if } \gamma\left(g_{2}\right) \leq \gamma\left(g_{1}\right),\end{cases}
$$

by v: $G \times G \rightarrow[0,1]$ is determined - fuzzy relation of expert competence. The value $v\left(g_{1}, g_{2}\right)$ is understood as the degree to which, in the opinion of the decision maker, the expert $g_{1}$ is more competent than the expert $g_{2}$.

After this, the problem reduces to a rational choice of alternatives from the set $X$, taking into account the information described above. According to [22], $\psi^{n . d} .\left(x_{i}, g\right)-$ defined as a fuzzy subset of non-dominated alternatives, corresponding to a fuzzy preference relation $\psi\left(x_{i}, x_{j}, g\right)$ ) with fixed $g \in G$ :

$$
\psi^{n . d .}\left(x_{i}, g\right)=1-\sup _{x_{j} \in X}\left[\psi\left(x_{j}, x_{i}, g\right)-\psi\left(x_{i}, x_{j}, g\right)\right] .
$$

The alternatives that give the largest possible value of the membership function $\psi^{n . d .}\left(x_{i}, g\right)$ on the set $X$ coincide with the individual solution of the $g$-th expert.

Further, the fuzzy relation $v\left(g_{1}, g_{2}\right)$ is generalized to the class of fuzzy subsets of the set $G$. The induced (generalized) fuzzy relation on the set $X$ is defined as follows:

$$
\eta\left(x_{i}, x_{j}\right)=\sup _{g_{1}, g_{2} \in G} \min \left\{\psi^{n . d .}\left(x_{i}, g_{1}\right), \psi^{n . d .}\left(x_{j}, g_{2}\right), v\left(g_{1}, g_{2}\right)\right\} .
$$

This fuzzy preference relation is the result of a "convolution" of a family of fuzzy relations $\psi\left(x_{i}, x_{j}, g\right)$ into a single resulting fuzzy preference relation, taking into account information about the competence of experts in a given subject area. 
Induced preference relations on the set $X$ make it possible to proceed to the problem of choosing alternatives with a single preference relation by defining the corresponding set of non-dominated alternatives.

$$
\tilde{\eta}^{\text {n.d. }}\left(x_{i}\right)=1-\sup _{x_{j} \in X}\left[\eta\left(x_{j}, x_{i}\right)-\eta\left(x_{i}, x_{j}\right)\right] .
$$

Finally, from the expression

$$
\eta^{n . d .}\left(x_{i}\right)=\min \left\{\tilde{\eta}^{n . d .}\left(x_{i}\right), \eta\left(x_{i}, x_{j}\right)\right\}
$$

the corrected fuzzy set of non-dominated alternatives is determined and an alternative is chosen that delivers the maximum of the $\eta^{\text {n.d. }}(x)$ function

$$
\eta^{n . d .}(x)=\sup _{x_{j} \in X} \eta\left(x_{i}\right)
$$

which is the most effective alternative. The selected alternative is the resulting group choice decision and coincides with one of the individual decisions.

\section{An empirical experiment on the fuzzy assessment of the demand for IT specialties}

For the practical implementation of the task of assessing the demand for IT professions and specialties used: a list of IT professions and specialties, based on the results of monitoring the IT segment of the labor market [9, 20]; data on IT professions and specialties, which are taught in the education system of Azerbaijan; codifier of professions and specialties ISCO08; statistics from the State Employment Service; vacancy announcements in open Internet resources; employers' applications for filling vacancies on the websites of recruitment agencies. As a result, the entire list of IT specialties is combined into 14 integrated groups of IT specialties.

Great importance has the formation of the selection criteria for evaluating the latter for comparison of IT specialties (alternatives). These criteria, on the one hand, should characterize IT specialties from the standpoint of the ratio of supply and demand in the market, on the other hand, should allow them to be ranked, i. e. ordering in ascending or descending order. In this case, the criteria characterizing the alternatives can be both quantitative (for example, wages for the specialty being assessed) and qualitative (for example, the imbalance of supply and demand).

For selection of criteria and scales for assessing priority IT specialties, discussions were held with leading experts-experts of the Institute of Information Technologies of the National Academy of Sciences of Azerbaijan (IIT ANAS), the Ministry of Education, IT industry and a list of the latter was compiled. As criteria applied to the assessment of IT specialties, the following are highlighted:

1. The degree of priority of the IT specialty, both in the context of the industry, and in other sectors of the economy $\left(k_{1}\right)$.

2. The imbalance of supply and demand in the context of IT specialties $\left(k_{2}\right)$.

3. Wages in the assessed IT specialty $\left(k_{3}\right)$.

4. The demand for the assessed IT specialties from the position of employment (IT specialists with a certain specialization are required to fill the declared vacancies) $\left(k_{4}\right)$.

5. Proposal for the assessed IT specialties from the position of employment (IT specialists with a specific specialization applying for the stated vacancies) $\left(k_{5}\right)$.

The procedure for assessing and streamlining alternatives (IT specialties) is as follows: experts are provided with a full list of alternatives to be assessed, as well as criteria, their terms (fuzzy grading scales) and the range of the latter. The task of the experts is in assessing each IT specialty on a set of criteria. When assigning the membership function for each criterion, on 
the one hand, it is necessary to assess the alternative for all criteria (by their set), on the other hand, to take into account the importance of the alternative for each individual criterion. When determining the membership functions $\phi_{k_{j}}\left(x_{i}\right)$, the criteria scale is used, which, regardless of the nature of the latter (qualitative or quantitative), determines their values in the interval $[0,1]$. Fuzzy assessment of criteria has convenient and understandable for experts qualitative gradations and their fuzzy correspondences, which take on the value from the area (range) of changes in terms (Table 1).

\section{Table 1}

The membership functions of fuzzy sets of verbal gradations of the linguistic variable "imbalance of supply and demand for IT specialties

\begin{tabular}{lcc}
\hline $\begin{array}{c}\text { The name of the criterion } \\
\text { (linguistic variable) }\end{array}$ & $\begin{array}{c}\text { Terms - fuzzy estimates of the linguistic variable } \\
\text { gradations "imbalance of supply and demand for } \\
\text { IT specialties" }\end{array}$ & $\begin{array}{c}\text { Range of change of membership } \\
\text { functions }\end{array}$ \\
\hline & Optimal (normative) imbalance & {$[0,8 ; 1]$} \\
Minimal imbalance & {$[0,6 ; 0,8)$} \\
Imbalance of supply and & Allowable imbalance & {$[0,4 ; 0,6)$} \\
demand for IT specialties & Critical Imbalance & {$[0,2 ; 0,4)$}
\end{tabular}

Taking into account the cumbersome fuzzy logic calculations for the full set of alternatives, the following is a practical implementation of the group decision-making method for their evaluation and ranking using a small dimension as an example.

Let $X=\left\{T_{1}, T_{2}, T_{3}, T_{4}, T_{5}, T_{6}\right\}$ - a given set of alternatives - IT professions and specialties. $K=\left\{k_{1}, k_{2}, k_{3}, k_{4}, k_{5}\right\}$ - criteria by which the alternatives are assessed. In this case, the following were selected as IT occupations and specialties: $T_{1}$ - programmer, $T_{2}-$ system analyst, $T_{3}$-information security specialist, $T_{4}$ - database administrator, $T_{5}-$ IT researcher, $T_{6}-$ network engineer.

The selection process involves 3 experts. The coefficients of expert competence in accordance with the preferences of the decision maker are expressed in the following values:

$$
\gamma\left(G_{1}\right)=0.9, \gamma\left(G_{2}\right)=1, \gamma\left(G_{3}\right)=0.9 \text {. }
$$

Tables 2-4 present the results of logical calculations of the degrees of satisfaction of a set of alternatives to a set of criteria according to the estimates of each of the three experts.

Table 2

Satisfaction degrees of the set of alternatives to the set of criteria according to the estimates of the first expert $G_{1}$

\begin{tabular}{|c|c|c|c|c|c|c|c|}
\hline$X$ & $k_{1}$ & $k_{2}$ & $k_{3}$ & $k_{4}$ & $k_{5}$ & $\min \phi_{k j}\left(T_{i}\right)$ & $\max \varphi\left(T_{i}\right)$ \\
\hline$T_{1}$ & 0 & 0.54 & 0.52 & 0.62 & 0.82 & 0 & - \\
\hline$T_{2}$ & 0 & 0.74 & 0.24 & 0 & 0.66 & 0 & - \\
\hline$T_{3}$ & 0.12 & 0.12 & 0.50 & 0.62 & 0.64 & 0.12 & 0.34 \\
\hline$T_{4}$ & 0.34 & 0.40 & 0.42 & 0.56 & 0.52 & 0.34 & - \\
\hline$T_{5}$ & 0.32 & 0.54 & 0.56 & 0.62 & 0.82 & 0.32 & - \\
\hline $\boldsymbol{T}_{6}$ & 0.24 & 0.32 & 0.46 & 0.54 & 0.52 & 0.24 & - \\
\hline
\end{tabular}


Table 3

Satisfaction degrees of the set of alternatives to the set of criteria according to the estimates of the second expert $G_{2}$

\begin{tabular}{|c|c|c|c|c|c|c|c|}
\hline$X$ & $k_{1}$ & $k_{2}$ & $k_{3}$ & $k_{4}$ & $k_{5}$ & $\min \phi_{k j}\left(T_{i}\right)$ & $\max \varphi\left(T_{i}\right)$ \\
\hline$T_{1}$ & 0.34 & 0.46 & 0.32 & 0.52 & 0.46 & 0.32 & - \\
\hline $\boldsymbol{T}_{2}$ & 0.8 & 0.24 & 0.44 & 0.72 & 0.46 & 0.08 & - \\
\hline$T_{3}$ & 0.36 & 0.32 & 0.34 & 0.44 & 0.32 & 0.32 & 0.32 \\
\hline $\boldsymbol{T}_{4}$ & 0.34 & 0.06 & 0.04 & 0.14 & 0.22 & 0.04 & - \\
\hline $\boldsymbol{T}_{5}$ & 0.36 & 0.32 & 0.26 & 0.26 & 0.22 & 0.22 & - \\
\hline$T_{6}$ & 0.64 & 0.44 & 0.24 & 0.42 & 0.36 & 0.24 & - \\
\hline
\end{tabular}

Table 4

Satisfaction degrees of the set of alternatives to the set of criteria according to the estimates of the third expert $G_{3}$

\begin{tabular}{|c|c|c|c|c|c|c|c|}
\hline$X$ & $k_{1}$ & $k_{2}$ & $k_{3}$ & $k_{4}$ & $k_{5}$ & $\min \phi_{k j}\left(T_{i}\right)$ & $\max \varphi\left(T_{i}\right)$ \\
\hline$T_{1}$ & 0.44 & 0.32 & 0.40 & 0.70 & 0.60 & 0.32 & - \\
\hline$T_{2}$ & 0.20 & 0.30 & 0.10 & 0.40 & 0.50 & 0.10 & - \\
\hline$T_{3}$ & 0.20 & 0.30 & 0.40 & 0.50 & 0.20 & 0.20 & - \\
\hline $\boldsymbol{T}_{4}$ & 0.10 & 0.10 & 0.16 & 0.30 & 0.04 & 0.04 & - \\
\hline $\boldsymbol{T}_{5}$ & 0.70 & 0.50 & 0.70 & 0.70 & 0.70 & 0.50 & 0.50 \\
\hline $\boldsymbol{T}_{6}$ & 0.50 & 0.50 & 0.60 & 0.70 & 0.36 & 0.36 & - \\
\hline
\end{tabular}

Here, the membership functions of the solution are determined by the intersection of the satisfaction degree of alternatives to the criteria, i. e.

$$
\phi\left(T_{i}\right)=\min _{T_{i} \in X}\left\{\phi_{k j}\left(T_{i}\right), j=\overline{1,5}\right\} .
$$

Alternatives satisfying the condition

$$
\max _{T_{i} \in} \phi\left(T_{i}\right)=\max _{T_{i} \in} \min \left\{\phi_{k j}\left(T_{i}\right), j=\overline{1,5}\right\},
$$

are the most effective solutions (popular IT specialties). In this case, the most effective solutions according to the estimates of the first expert $G_{1}$ are the alternative $T_{4}$, according to the estimates of the second expert $G_{2}$-alternatives $T_{1}$ and $T_{3}$, according to the estimates of the third expert $G_{3}-$ alternative $T_{5}$.

On the basis of formula (5), a comparison of alternatives is carried out, the results of which for each of the experts are described by the matrices of the non-strict preference, presented in Tables 5-7. 
Table 5

Relationships of non-strict preferences according to expert $G_{1}$

\begin{tabular}{|c|c|c|c|c|c|c|}
\hline$T_{i}$ & $T_{1}$ & $T_{2}$ & $T_{3}$ & $T_{4}$ & $T_{5}$ & $T_{6}$ \\
\hline$T_{1}$ & 1 & 1 & 0.88 & 0.66 & 0.68 & 0.76 \\
\hline$T_{2}$ & 1 & 1 & 0.88 & 0.66 & 0.68 & 0.76 \\
\hline$T_{3}$ & 1 & 1 & 1 & 0.78 & 0.8 & 0.88 \\
\hline$T_{4}$ & 1 & 1 & 1 & 1 & 1 & 1 \\
\hline$T_{5}$ & 1 & 1 & 1 & 0.98 & 1 & 1 \\
\hline$T_{6}$ & 1 & 1 & 1 & 0.9 & 0.92 & 1 \\
\hline
\end{tabular}

Table 6

Relationships of non-strict preferences according to expert $G_{2}$

\begin{tabular}{|c|c|c|c|c|c|c|}
\hline$T_{i}$ & $T_{1}$ & $T_{2}$ & $T_{3}$ & $T_{4}$ & $T_{5}$ & $T_{6}$ \\
\hline$T_{1}$ & 1 & 1 & 1 & 1 & 1 & 1 \\
\hline$T_{2}$ & 0.76 & 1 & 0.76 & 1 & 0.86 & 0.84 \\
\hline$T_{3}$ & 1 & 1 & 1 & 1 & 1 & 1 \\
\hline$T_{4}$ & 0.72 & 0.96 & 0.72 & 1 & 0.82 & 0.80 \\
\hline$T_{5}$ & 0.9 & 1 & 0.9 & 1 & 1 & 0.98 \\
\hline$T_{6}$ & 0.92 & 1 & 0.92 & 1 & 1 & 1 \\
\hline
\end{tabular}

Table 7

Relationships of non-strict preferences according to expert $G_{3}$

\begin{tabular}{cccccccc}
\hline$T_{i}$ & $T_{j}$ & $T_{1}$ & $T_{3}$ & $T_{4}$ & $T_{5}$ & $T_{6}$ \\
& $T_{1}$ & 1 & 1 & 1 & 1 & 0.82 & 0.96 \\
$T_{2}$ & 0.78 & 1 & 0.9 & 1 & 0.6 & 0.74 \\
$T_{3}$ & 0.88 & 1 & 1 & 1 & 0.7 & 0.54 \\
$T_{4}$ & 0.72 & 0.94 & 0.84 & 1 & 1 & 1 \\
$T_{5}$ & 1 & 1 & 1 & 1 & 0.85 & 1
\end{tabular}

Competence of experts is described using the fuzzy relationship matrix "not less important", calculated by the formula (6):

$$
\left(\begin{array}{ccc}
1 & 0.9 & 1 \\
1 & 1 & 1 \\
1 & 0.9 & 1
\end{array}\right)
$$


The set of non-dominated alternatives, reflecting respectively the ratio of preferences of each expert, is presented in the form of a matrix:

$$
\left(\begin{array}{cccccc}
1 & 1 & 1 & 1 & 0.98 & 0.9 \\
0.78 & 1 & 0.9 & 1 & 0.9 & 0.92 \\
0.88 & 1 & 1 & 1 & 1 & 0.86
\end{array}\right) .
$$

Further, using the expression (8)

$$
\eta\left(T_{i}, T_{j}\right)=\operatorname{supmin}_{g_{1}, g_{2} \in G}\left\{\phi^{n . d .}\left(T_{i}, g_{1}\right), \phi^{n . d .}\left(T_{j}, g_{2}\right), v\left(g_{1}, g_{2}\right)\right\}
$$

let's obtain the matrix of the induced preference relation on the set of alternatives (Table 8).

Table 8

Matrix of induced preference relationship on the set of alternatives

\begin{tabular}{cccccccc}
\hline$T_{\boldsymbol{i}}$ & $\boldsymbol{T}_{j}$ & $\boldsymbol{T}_{\mathbf{1}}$ & $\boldsymbol{T}_{\mathbf{2}}$ & $\boldsymbol{T}_{\mathbf{3}}$ & $\boldsymbol{T}_{\mathbf{4}}$ & $\boldsymbol{T}_{\mathbf{5}}$ & $\boldsymbol{T}_{\mathbf{6}}$ \\
& $\boldsymbol{T}_{\mathbf{1}}$ & 1 & 0.76 & 1 & 1 & 1 & 1 \\
$\boldsymbol{T}_{2}$ & 0.76 & 0.76 & 0.76 & 0.76 & 0.76 & 0.76 \\
$\boldsymbol{T}_{3}$ & 1 & 0.76 & 1 & 1 & 1 & 0.92 \\
$\boldsymbol{T}_{\mathbf{4}}$ & 1 & 0.36 & 0.9 & 0.98 & 1 & 0.9 \\
$\boldsymbol{T}_{\mathbf{5}}$ & 0.9 & 0.76 & 0.9 & 0.92 & 0.92 & 0.9 \\
$\boldsymbol{T}_{\mathbf{6}}$ & 0.92 & 0.76 & 0.92 & & & 0.92
\end{tabular}

The expression (9) allows to select an unadjusted set of non-dominated alternatives:

$$
\begin{aligned}
& \tilde{\eta}^{\text {n.d. }}\left(T_{i}\right)=1-\sup _{T_{i} \in X}\left[\eta\left(T_{j}, T_{i}\right)-\eta\left(T_{i}, T_{j}\right)\right],
\end{aligned}
$$

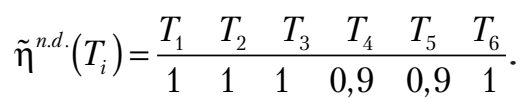

Finally, using formulas (10), (11), the corrected fuzzy set of non-dominated alternatives is determined and an alternative is chosen that delivers the maximum of the function $\eta^{\text {n.d }}(\mathrm{x})$ :

$$
\begin{aligned}
& \eta^{\text {n.d. }}\left(T_{i}\right)=\min \left\{\tilde{\eta}^{\text {n.d. }}\left(T_{i}\right), \eta\left(T_{i}, T_{j}\right) ; \quad \eta^{\text {n.d. }}(T)=\max \eta^{\text {n.d }}\left(T_{i}\right)\right\}
\end{aligned}
$$

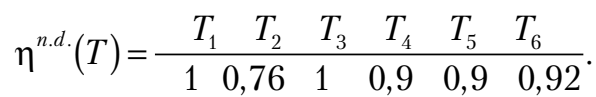

The obtained results allow to conclude that the choice of alternatives $T_{1}$ and $T_{3}$ is rational in this case. This means that the specialties "programmer" and "information security" are the most demanded in the labor market. By priority, alternatives are ranked in the following order: $T_{1}, T_{3}, T_{6}, T_{4}, T_{5}, T_{2}$. In accordance with this ranking, let's obtain the following ordering of IT professions and specialties:

1. Programmer.

2. Information security specialist. 
3. Network engineer.

4. Database administrator.

5. IT researcher.

6. System analyst.

Expert assessment and fuzzy logical calculations using the proposed methods for all 14 evaluated groups of IT specialties allowed the latter to be streamlined according to the degree of their relevance in the labor market:

1. Programmer.

2. Programmer-developer (Web, SQL, JavaScript, Linux, etc.).

3. Information security specialist.

4. Information systems specialist.

5. Network engineer.

6. System administrator.

7. Database administrator.

8. IT manager.

9. Sales and marketing manager of solutions and complex technical systems.

10. Consultant for the implementation of IT solutions.

11. IT researcher.

12. Electronic engineer.

13. System analyst.

14. System architect.

Testing the effectiveness of the proposed approach was carried out by comparative analysis with the results of monitoring supply and demand for IT specialties [9, 20], as well as with the professional orientation of IT vacancies announced in open Internet resources on the websites of employment services and recruiting agencies [23-26]. The analysis of the vacancy dynamics in the above mentioned IT specialties confirms by $80-85 \%$ the obtained ordering, i. e. IT specialties that fall into the category of priority according to the proposed assessment methodology are also the most demanded in the labor market.

\section{Conclusions}

Identifying the demand for IT professions and specialties that are most in demand in the labor market makes it possible to determine the current and forecast the future structure and volume of supply for them. This factor should be taken into account when determining the reference figures for admission of students to universities in the context of IT specialties, which are often not sufficiently substantiated from the standpoint of supply and demand in the labor market.

The methodical approach proposed in the article for assessing the demand for IT professions and specialties can support various users (employees of government bodies responsible for labor market policy and training, educational institutions, employers, individuals, employment counselors, HR departments, applicants) in obtaining scientifically based information about the real needs of the IT segment of the labor market and, accordingly, in making scientifically based decisions.

The methods of minimizing the structural imbalance of supply and demand for IT specialties form the mathematical basis of one of the components of the IT specialists' intellectual labor market system designed at IIT ANAS. The purpose of the system is in support of the adoption of scientifically based management decisions to eliminate various types of mismatch of supply and demand in the IT segment of the labor market.

\section{References}

[1] Eurostat regional yearbook (2018). doi: http://doi.org/10.2785/231975

[2] Pilot project monitors online vacancies for ICT specialists in real-time (2018). Available at: https://ec.europa.eu/digital-single-market/en/news/pilot-project-monitors-online-vacancies-ict-specialists-real-time

[3] European Jobs Monitor (2018). Available at: https://www.eurofound.europa.eu/data/european-jobs-monitor 
[4] Ticol, D. (2012). Labour supply/demand dynamics of Canada's information and communications technology (ICT) sector. Final Report /Nordicity, 30.

[5] Wennergren, D. M. (2007). Forecast of Future IT Labor Supply and Demand. U.S. Available: https://dodcio.defense.gov/Home/ Initiatives/NetGenerationGuide/ForecastofFutureLaborSupplyandDemand/

[6] Avram, A. (2014). IDC Study: How Many Software Developers Are Out There? Available at: https://infoq.com/news/2014/01/ IDC-software-developers

[7] Defitsit IT-spetsialistov v 2015 godu sostavit 170 tysyach chelovek. UNIAN. Available at: https://www.unian.net/society/ 871034-defitsit-it-spetsialistov-v-2015-godu-sostavit-170-tyis-chelovek-gosinformnauki.html

[8] IT-kadry 2010. Chislennost' zanyatyh v rossiyskoy ekonomike 2009 g. i prognoz potrebnosti na 2010-2015 gg. Available at: https://apkit.ru/files/personal2009_final.pdf

[9] Mammadova, M., Mammadzadeh, F., Jabrayilova, Z. (2016). Supply and demand in it-segment of Azerbaijan labor market. Problems of Information Technology, 07 (2), 91-106. doi: https://doi.org/10.25045/jpit.v07.i2.11

[10] Mammadova, M., Mammadzada, F. (2018). Development of the technique of assessing the total number of it professionals in Azerbaijan. Problems of Information Technology, 09 (1), 53-64. doi: https://doi.org/10.25045/jpit.v09.i1.06

[11] Mammadova, M., Mammadzada, F. (2018). Analysis technique of it-profile education and matching of supply and demand for it specialists. Problems of Information Society, 09 (1), 26-36. doi: https://doi.org/10.25045/jpis.v09.i1.02

[12] Mammadova, M. H., Jabrayilova, Z. G., Mammadzada, F. R. (2015). Managing the IT labor market in conditions of fuzzy information. Automatic Control and Computer Sciences, 49 (2), 88-93. doi: https://doi.org/10.3103/s0146411615020030

[13] Mammadova, M., Jabrayilova, Z. (2018). Methodological approach to the human resource management in virtual organizations. EUREKA: Physics and Engineering, 3, 3-11. doi: https://doi.org/10.21303/2461-4262.2018.00642

[14] State Program "Azerbaijani youth in 2011-2015" Approved by the Order of the President of the Republic of Azerbaijan dated on July 7, 2011. Available at: http://www.youthpolicy.org/national/Azerbaijan_2011_Youth_State_Program.pdf

[15] Concept of Development Azerbaijan 2020: Look into the Future. Decree of the President of the Republic of Azerbaijan of December 29, 2012. Available at: http://president.az/files/future_az.pdf

[16] National Strategy for Information Society Development in the Republic of Azerbaijan for 2014-2020 (2014). Order of the President of the Republic of Azerbaijan dated. Available at: http://president.az/articles/11312

[17] Strategic Roadmap for the Development of Telecommunications and Information Technology (2016). Decree of the President of the Republic of Azerbaijan. Available at: http://president.az/articles/22382

[18] Zadeh, L. A. (1975). The concept of a linguistic variable and its application to approximate reasoning - I. Information Sciences, 8 (3), 199-249. doi: https://doi.org/10.1016/0020-0255(75)90036-5

[19] Simon, H. A. (1973). The structure of ill structured problems. Artificial Intelligence, 4 (3-4), 181-201. doi: https://doi.org/ 10.1016/0004-3702(73)90011-8

[20] Mammadova, M. H. (2019). Intelligent management of the labor market of IT specialists. Baku: "Information Technologies" publishing house, 298.

[21] Mammadova, M. H. (1997). Decision-making based on knowledge bases with fuzzy relational structure. Baku: Elm, 296.

[22] Orlovskiy, S. A. (1981). Problemy prinyatiya resheniy pri nechetkoy iskhodnoy informatsii. Moscow: Nauka, 208.

[23] Rabota.az. Available at: https://www.rabota.az/

[24] Boss.az. Available at: https://boss.az/

[25] Jobsearch.az. Available at: http://www.jobsearch.az/

[26] E-mlspp. Available at: https://e-mlspp.gov.az/ 